Session 1526

\title{
Internet Based Curriculum Innovation in Information Engineering and E-Business: The Integrated Curriculum Delivery System
}

\author{
Amy R. Pritchett, Alexander B. Quinn, George Nickles, \\ Mahima Ashok, Mark Iken, J. C. Lu \\ School of Industrial and Systems Engineering \\ Georgia Institute of Technology
}

\section{Introduction}

The current compartmentalization of educational material into courses limits a student's ability to quickly and easily access information from a variety of topics, explore new topics, and review prerequisite knowledge once in more advanced courses. In a larger sense, students may not understand the relationships between material presented in different courses, and therefore not develop an understanding of the fundamental relationship between concepts in their area of study. The compartmentalization of material is a result of physical and temporal expediency, including the practical need to delineate faculty responsibilities, the lack of a standardized method for referencing material between courses, and the specialization within individual academic domains. As a result, ascertaining the relationships between common concepts occurring within and between disciplines becomes a challenge for students.

Considering the limited resources of educators and students, a technological solution is proposed to address the problems with concept learning in individual courses. A set of software tools has been developed to design, deliver, and evaluate course material through the Internet. The software tools also provide a means of relating material between different courses to promote conceptual learning within and between courses. As such, these tools employ the concepts of curriculum integration and are termed the Integrated Curriculum Delivery System. Thus, by integrating the knowledge content of distinct courses into a unified whole, the Integrated Curriculum Delivery System seeks to provide information to educators and students in a manner that will support deeper conceptual understanding.

This document begins with an overview of curriculum integration and its potential for promoting concept learning. A discussion of the software tools created for the Integrated Curriculum Delivery System follows. The system is currently in development at the Georgia Institute of Technology for the design, delivery and evaluation of an integrated curriculum in Information 
Technology and E-Business. The courses currently supported by the system and additional tools under development are also briefly discussed.

\section{Curriculum Integration}

The traditional organization of a curriculum into standardized courses limits the extent that students can perceive and understand the relationship between concepts, and makes it difficult for students to explore concepts in an interdisciplinary manner. For example, newer concepts covered at the end of a course are not likely to be covered in the curriculum again unless courses specifically build upon one another. Also, topics from courses that are not clearly related to the rest of the curriculum do not benefit from conceptual reinforcement or the explicit description to students of their relationship to topics in their mainstream courses.

An integrated curriculum, which highlights the relationships between concepts, is better suited to conceptual reinforcement and knowledge exploration. Essentially, an integrated curriculum emphasizes the teaching of between-topic relationships in addition to the teaching of topics themselves. In an integrated curriculum, the focus on the context of knowledge is believed to enhance the learning of the underlying educational content. Integrated curricula are generally considered to improve the meaningfulness of learning experiences, encourage both depth and breadth in knowledge acquisition, and help students apply skills to realistic situations. ${ }^{1}$ Furthermore, integrated curricula emphasize knowledge exploration, learning relationships between subjects, interdisciplinary study, and problem-based learning. This learning focus parallels the desired change from traditional educational methods to authentic, goal-oriented learning methods. ${ }^{2}$ Rather than treating each course as an independent entity, an integrated curriculum brings courses together to emphasize between-course relationships and encourage deeper conceptual understanding. As the relationships between topics become more apparent, students may better conceptualize their development of knowledge within a curriculum.

Throughout educational research, curriculum integration has assumed an inclusive interpretation, extending beyond its initial conception as a combining of disciplines. ${ }^{3}$ Included in the interpretation are the integration of skills such as problem solving, thinking, and reasoning. Unplanned, localized forms of integration between two naturally converging disciplines (e.g., biopsychology) as well as fully planned forms of school-wide integration efforts are considered relevant to curriculum integration. ${ }^{4}$ The use of information technology to establish an integrated curriculum is proposed as an extension of the interpretation, wherein topic relationships can be emphasized without necessarily altering the basic structure of the courses.

\section{The Integrated Curriculum Delivery System}

The Integrated Curriculum Delivery System is a comprehensive set of web-based tools currently under development that enables the learning behaviors inherent to an integrated curriculum. These tools enhance the educational process for both the teacher and the student by facilitating pedagogical specialization as well as concept comprehension. By establishing connectivity within an educational framework, the Integrated Curriculum Delivery System provides students a

Proceedings of the 2002 American Society for Engineering Education Annual Conference \& Exposition Copyright $\odot$ 2002, American Society for Engineering Education 
means by which to participate in an ongoing and connected learning process. Within the Integrated Curriculum Delivery System, previously encountered concepts become more concrete and emerging concepts can be more easily explored.

The web-based software tools access a database containing the educational materials. The educational materials may be in any Internet readable form such as webpages, images, interactive demos, etc. The software tools can be used to create websites for traditional courses, inject specialized online course components, and provide exploration sites for students and refresher sites for professionals as a means of continuing education (Figure 1). Users can access the educational materials in multiple ways, including concept maps, search techniques, and the standard course structure. The database of references to the material is key in achieving multiple means of access to the educational content.

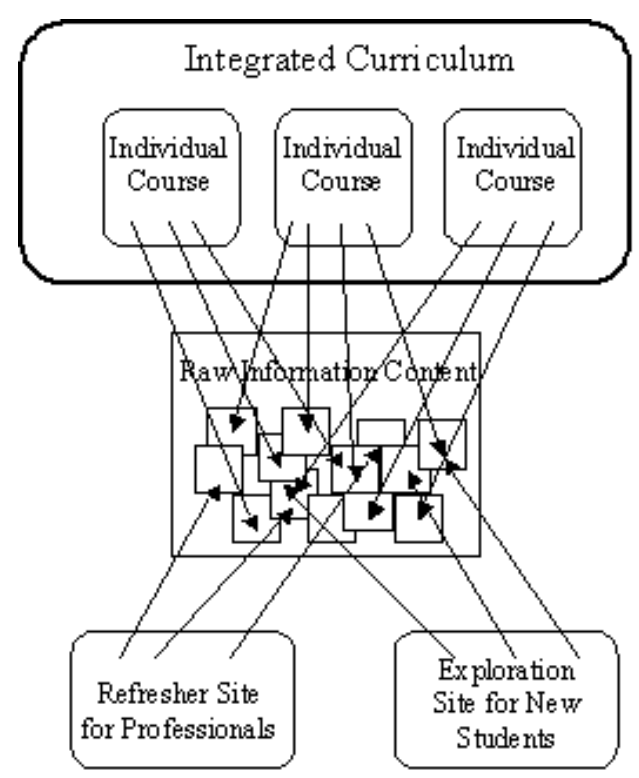

Figure 1. Schematic of Integrated Curriculum Information Storage and Access

Several types of users will be supported by the Integrated Curriculum Delivery System, including educators, current students, alumni, and professionals. Educators primarily use the system to create and support courses. By generating courses, educators also serve as the primary generators of educational material in the system. The primary means of access for educators are the course webpages they are responsible for managing. When adding content to the system, educators will also determine what materials in the database are related to the content they are adding. In the process of adding material, educators also see how their course topics relate to other topics in the system. They will also have the opportunity to incorporate any additional content into their courses or provide links to the related materials. As such, educators also become consumers of the material provided by other educators.

Proceedings of the 2002 American Society for Engineering Education Annual Conference \& Exposition Copyright ( 2002, American Society for Engineering Education 
Current students will also use the course webpages to guide their initial interaction with the system. Students can view materials, complete assignments, and receive grades. As the system is developed further, students will also have the opportunity to explore topics from other courses through related topic links, concept maps, and keyword searches. As students complete additional courses, the system will track their progress through the content in the system. This tracking will also allow the system to tailor the presentation of information to the students based on their knowledge and past experiences with the system.

While traditional educational technology tools typically do not provide long-term support, the Integrated Curriculum Delivery System will retain knowledge of the student, the courses they took, and the format and content of the websites that they interacted with in these courses. This persistence allows course alumni to benefit from reference to material from previous courses as they experienced them. This function creates a role for the university in more actively supporting lifelong learning of their alumni. Our objective is that longtime users of the system will be able to review their previous experience as reinforcement of material, and to have highlighted updates in knowledge in the domain in a presentation relative to the knowledge they have gained so far.

Outside of a normal course structure, exploration and refresher sites allow motivated individuals (including professionals seeking continuing education) to enter the system seeking specific knowledge and to be provided with relevant materials from a range of courses. Studies of webbased instruction in college education suggest that such well-motivated learners have the skills to benefit from the use of asynchronous, geographically distant educational resources. ${ }^{5}$ Likewise, students new to a program can explore its curriculum and gain insight into its general theme and topic areas.

The information presented to the user is tailored according to their immediate needs as well as previous interaction with the system. The ability to personalize the presentation of information to the user can be used to promote a balanced understanding of the educational content when the user may have a fragmented and partial knowledge of related concepts. Thus, with the inception of an integrated curriculum via information technology, the information content becomes a collective source for knowledge access and acquisition. As such, the same underlying intellectual content can have many different apparent 'structures' to suit the differing needs of students, explorers, and professionals.

The tools developed for the Integrated Curriculum Delivery System contain an essential component of data management based on individual preferences and historical interaction with the system. For example, new information related to frequent searches by the user may be given priority over new information unconnected to previous searches.

This emphasis on a persistent, continuously evolving database of instruction material is the key element for providing all of these capabilities. However, as the amount of information and user data gradually increases, structured data management becomes more important. For example, the elimination of outdated material from the knowledge base must be handled in a logical

Proceedings of the 2002 American Society for Engineering Education Annual Conference \& Exposition Copyright $\odot$ 2002, American Society for Engineering Education 
manner. Likewise, peer review between instructors of the educational content they provide may be beneficial. Therefore, we also plan to build functionality into the same data management tools as the amount of instructional material in our database grows.

\section{Integrated Curriculum Delivery System Components}

Typical use of the Internet in most courses consists of posting syllabi or assignments. ${ }^{6}$ The Integrated Curriculum Delivery System currently provides core course management tools for these functions. In addition, on-going development is working to highlight relationships and linkages between concepts through the inclusion of several tools: the course topic tool, the search function, concept maps, and links to other topics.

The course topic tool is central to the Integrated Curriculum Delivery System. Instructors are asked to apportion course notes into 'topics' before entering information into the system. Each topic should focus on a single concept in a short lesson; topics can be further categorized as definition and description, derivation, example or application, etc. This format allows information to be selected according to the user's needs when searching for the database. For example, students can search for examples of related topics to a concept introduced in lecture, and professionals can search for definition and description of terms and theories that they have been asked to apply in their careers. When uploading topics to the system, the instructors are asked to provide information about them. This information is added to the topic database and is used to determine related topics, proceeding and succeeding topics, to highlight related material when viewing a topic, and to support topic searches based on format, method of instruction, etc.

The search function, concept maps, and hyperlinks on the topic information pages will provide interfaces into the topic database. The search function can use a variety of mechanisms, including keyword searches, descriptions of related topics and requests for certain formats or methods of instruction to retrieve relevant topics. The concept map is a visual display of the networked relationships of topics, showing visually a topic's prerequisites, examples, and other linked items. Related topics may be identified in the current course or from other courses in the curriculum. In these displays and next to the display of topics are links that allow users to jump to related topics or to material presenting the same concept in a different manner (e.g., from providing a definition to providing an example).

As noted earlier, the system supports more traditional course activities. To make the system an integral part of their associated courses, these activities are currently implemented so the system can serve as each course's website (see Figure 2 for a snapshot of a current course website). The announcements tool allows instructors to display messages to all students in the course. The syllabus tool allows instructors to upload a syllabus and make it available to students. The course roster component allows instructors to manage the students registered for the course. The file management tool allows instructors to manage all files uploaded to the system. The calendar component provides a listing of course events (for example, assignment due dates) in date order. The gradebook component allows instructors and students to manage assignments and grades.

\section{Proceedings of the 2002 American Society for Engineering Education Annual Conference \& Exposition} Copyright $\odot$ 2002, American Society for Engineering Education 
The information content supporting these tools is contained in multiple tables of a MySQL database and allows significant cross-talk between tools.

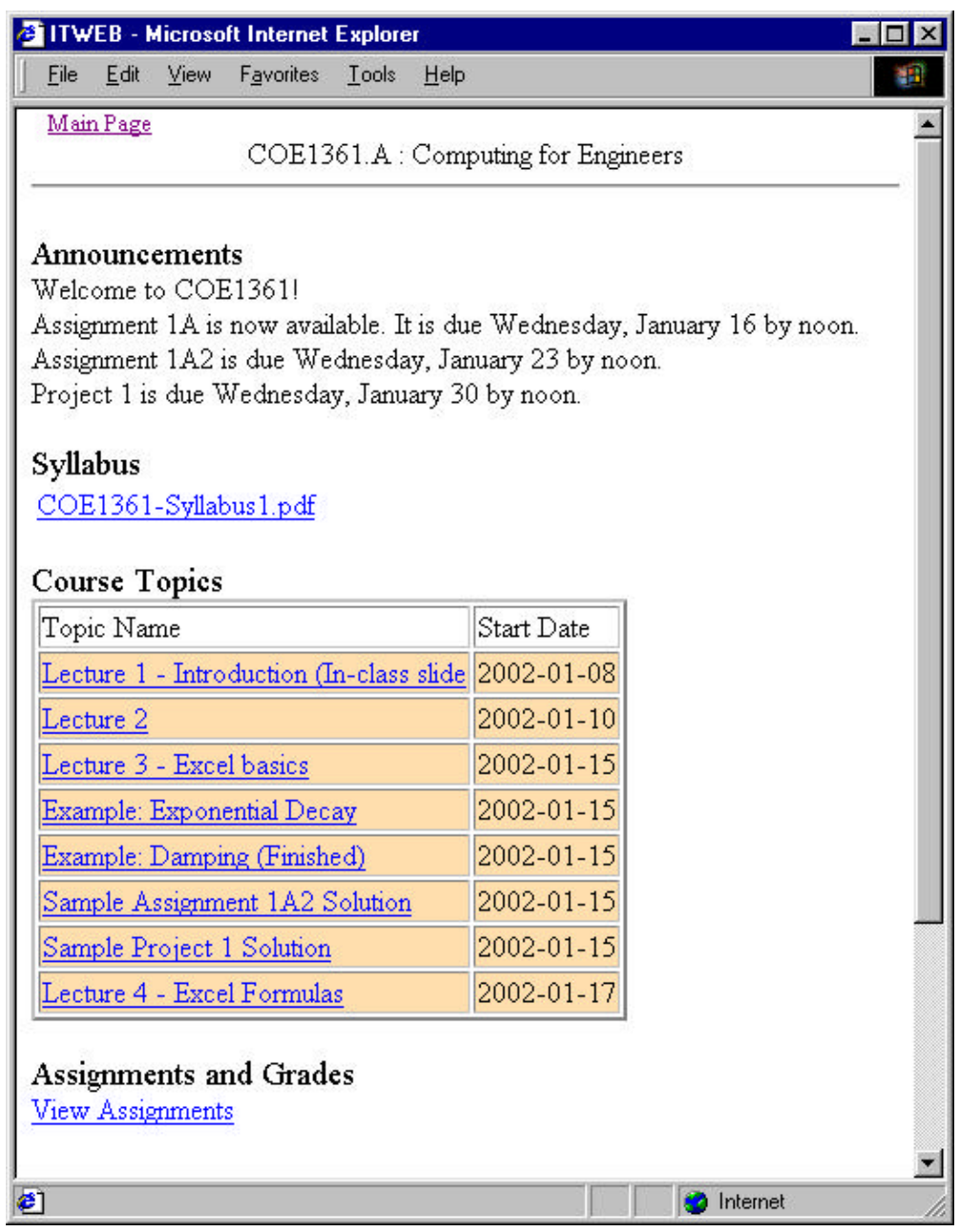

\section{Figure 2: A Course Website Generated by the Integrated Curriculum Delivery System}

The tools in the system enable educators and students to have different privileges as determined by course managers (which may include instructors and/or teaching assistants). The instructor is capable of configuring many features of the course website, and to determine the privileges of the students. For instance, the instructor has the ability to view the grades of all students and to make modifications to grades. Students typically view only their own grades in a read-only format, but may also be permitted to send comments to the instructor or record their own comments about the assignments for later use. Likewise, the instructor may choose to allow the students to see the course roster or other ad ministrative elements of the course.

Additional components to support communication between users of the system are in development and may be included at the discretion of the course manager. These components

Proceedings of the 2002 American Society for Engineering Education Annual Conference \& Exposition Copyright ( 2002, American Society for Engineering Education 
will include discussion boards and chat functions to allow interaction between users. Email functions will also be added to allow, for example, instructors to email the entire course or individual students. A homework-compare component will allow students to view the submissions of other students and provide feedback to one another. These communications components are included to support the development of online communities related to both courses and specific topic areas.

The inclusion of learners in making contributions to the collective knowledge base elevates their role in learning from passive receivers of presented material to active authors of educational content. This ability to express their nascent understanding and see that of their fellow learners may be viewed as an asynchronous method of dialogue between learners, and between learners and instructors. Therefore, homework and assignments uploaded into the system are treated as contributions to the database of instructional material. It is also anticipated that industry participants will enrich the system by contributing case studies and example applications.

Additional on-going development plans include methods of dealing with intellectual property considerations, especially as more courses are added to the system. Each piece of intellectual content will be classified by ownership and will account for restrictions on distribution. Also, tracking faculty content contributions to the topic database along with peer and student ratings is planned. This serves as a means of giving credit to those who actively make contributions to the system and provides a means of supervising and rating the content available.

\section{Evaluation of the Integrated Curriculum Delivery System}

Paralleling the lack of use of web-based educational technology tools is the lack of evaluation of such tools in terms of utility and effectiveness. ${ }^{6}$ A systematic and rigorous evaluation incorporating three types of assessment (planning, formative and summative) is imbedded in the Integrated Curriculum Delivery System. Planning assessment helps define the goals and functions of the tools with specificity, which in turn enables the definition of objective measurements in the later forms of assessments. The formative evaluation is a dynamic process of continuous improvement through corrective remedial measures. Formative evaluation will include identifying relational information not captured by information organization tools and the usefulness of specific relationship presenting tools to learners and the significance of learner input to the integrated curriculum. Formative evaluation, which may take place during development and implementation, is valuable in improving instruction and therefore the system as a whole. Summative evaluation judges the effectiveness of an educational system after completing one or more cycles of operation.

Evaluation tools are currently being automated into the system. Their functioning is transparent, as far as is possible, to the learners, with the exception of pop-up forms for rating instructional material and sending anonymous feedback to the instructor. This evaluation support is intended to guide the instructor in preparing and analyzing a variety of measurements of the system, their course website, and specific elements of instructional material. Also, the tasks and distributing, processing, and analyzing of the results of each measurement and integrating results from each

Proceedings of the 2002 American Society for Engineering Education Annual Conference \& Exposition Copyright $\odot$ 2002, American Society for Engineering Education 
into a cohesive report are conducted automatically. Feedback is provided immediately to the instructor so changes can be made during the term, rather than waiting until the end of the term to identify and correct problems. Also, the resolution of the evaluation can be adjusted to focus on a large or small section of the system. Most importantly, the various measurements are integrated not only into one interface but also into aggregate measures of effectiveness giving feedback to instructors at a glance. These assessment tools are documented more completely by Nickles and Pritchett. ${ }^{7}$

\section{Courses Currently Supported by the Integrated Curriculum Delivery System}

The Integrated Curriculum Delivery System has been incorporated into several courses at the Georgia Institute of Technology. As an example of the diverse range of courses using the system, a senior-level Industrial Engineering design course in human-integrated systems, an introductory computing course, a junior-level course on supply-chain management logistics and a graduate level course in manufacturing systems are currently using the system. As the design of the system is finalized, it will be made available to all faculty in the Georgia Tech's School of Industrial and Systems Engineering and, ultimately, distributed to the engineering education community at large.

A related objective of this project is to lay the foundation for an integrated curriculum in information technology and E-business. As companies redefine their objectives and restructure their operations to compete more effectively in the E-business marketplace, there will be considerable demands for well-trained "knowledge engineers" that understand how to do business electronically ("E-business") and how to synthesize large volumes of data into useful decision-making knowledge. Although there is a compelling need for education in information technology and E-business, at present engineering programs are not commonly involved in developing courses or curriculum that address these needs. Instead, many of the available programs are limited to management or computing, and therefore tend to be limited to either technology aspects or management and commerce aspects. The educational materials developed toward this objective will be suitable for supporting an interdisciplinary curriculum in information technology, for self-exploration by interested learners, and for structured early career support. It will thus provide a working demonstration of the curricular innovations and tools described previously, promoting their use in a specified domain. The novelty of this curriculum lends itself well to use of the Integrated Curriculum Delivery System, as its instructional material and courses can be included in it from the start, rather than requiring modification or re-development of course materials in appropriate electronic forms.

Several different courses are currently under development for this project. A senior-level introductory course to Information Systems has been developed, and instructional material is being developed for courses in E-Business, data-mining and Enterprise Resource Systems. In addition, established courses in supply chain management, manufacturing logistics, decision support and computing are being integrated into the curriculum and into the Integrated Curriculum Delivery System.

\section{Proceedings of the 2002 American Society for Engineering Education Annual Conference \& Exposition} Copyright (C) 2002, American Society for Engineering Education 
Ultimately, it is hoped that this integrated curriculum will lead to a graduate program in information technology and E-business involving many faculty and graduate students. As the curriculum grows, other likely contributors will include courses in intelligent knowledge networks, workflow automation, Internet data, information and knowledge mining, E-security and data integrity, and on-line analytical processing. Commensurate with the growth of the number of courses will be the content of the integrated electronic curriculum and its ability to support both exploration by students, as well as early career support for professionals in conjunction with established executive graduate programs, continuing education, and short courses.

\section{Conclusion}

The integrated curriculum envisaged by this project seeks to provide an evolving database of course concepts and instructional material, thereby making access to knowledge easy and efficient. In doing so, it actively involves the learner in an interactive process of integrated education. A steady and sustained assessment of the design is planned at the preliminary, formative, and summative stages of the evolution of the curriculum whereby the system can function more effectively.

Furthermore, methods of creating innovative curriculums have been examined, not only towards the development of educational technology tools for integrated curriculums, but also for general knowledge exploration and structured early career support for professionals. Particular emphasis will be given to the diverse ways students can use the system to promote lifelong learning. In addition, instructor ability to manage content and evaluate system effectiveness continually improves the quality and quantity of information provided to students by the system. These benefits will take place both within and external to the development of an integrated curriculum in information technology and E-business.

Currently, the Integrated Curriculum Delivery System is in the "beta test" stage. Thus far, its incorporation into courses at Georgia Tech has served primarily within the standard course model. Tools for online assessments and curriculum integration remain under development and will be incorporated as the educational content in the database expands. Thus, the expansion of system capabilities will occur in parallel with the expansion of the underlying knowledge base.

\section{Acknowledgements}

This research is sponsored by grant \#EEC-0080315 from the National Science Foundation.

\section{Bibliography}

1. $\quad$ K. Lake, "Integrated Curriculum," School Improvement Research Series, vol. 8, no. 16, (1993).

2. J. Ingram, "Curriculum Integration and Lifelong Education," UNESCO Institute for Education, London, (1979).

Proceedings of the 2002 American Society for Engineering Education Annual Conference \& Exposition Copyright $\odot$ 2002, American Society for Engineering Education 
3. A. Relan and R. Kimpston, "Curriculum Integration: A Critical Analysis of Pratical and Conceptual Issues," Integrating the Curricula: A Collection. R. Fogarty (ed.), IRI/Skylight Publishing, Inc., Palatine, Illinois, (1993).

4. J. Beane, "Curriculum Integration: Designing the Core of Democratic Education," Teachers College Press, New York, (1997).

5. S.R. Hiltz, "Correlates of Learning in a Virtual Classroom", International Journal of Man-Machine Studies, vol. 39, p. 71-98, (1993).

6. G. Nickles, A. Pritchett, and L. Trotti, "Methods of Measuring Teaching Effectiveness in the Classroom and on the Internet: A Survey of Engineering Instructors," presentation at American Society of Engineering Education, Albuquerque, NM, (2001).

7. G. Nickles and A. Pritchett, "Software for the Automated Evaluation of Web-Delivered Instruction," presentation at American Society of Engineering Education, Montreal, Quebec (2002).

\section{Biographical Information}

\section{AMY PRITCHETT}

Amy Pritchett is an Assistant Professor in the School of Industrial and Systems Engineering, and a Joint Assistant Professor in the School of Aerospace Engineering, at Georgia Tech. She received her S.B., S.M. and Sci.D. from MIT's Department of Aeronautics and Astronautics. Her research specializes in the design of complex human integrated systems, including cockpit design and educational technology.

\section{ALEXANDER QUINN}

Alexander Quinn is a PhD student in the School of Industrial and Systems Engineering at Georgia Tech with an emphasis in Human-Integrated Systems. He received a B.S in Industrial Engineering and Management Systems and a B.S. in Psychology from the University of Central Florida and a M.S. in Industrial Engineering from Georgia Tech. His research interests include cognitive engineering and the design of educational technology.

\section{GEORGE NICKLES}

George Nickles is a PhD student in the School of Industrial and Systems Engineering at Georgia Tech with an emphasis in Human-Integrated Systems. He received his B.S and M.S. in Industrial Engineering from Clemson University. His research interests include cognitive engineering, educational technology, evaluation, and training.

\section{MAHIMA ASHOK}

Mahima Ashok is a Master's student in the School of Industrial and Systems Engineering at Georgia Tech. She received her B.S. in Computer Engineering from Georgia Tech and has experience in the field of Internet applications and software development. Her interests include human-computer interaction and design of Internetbased tools.

\section{MARK IKEN}

Dr. Mark Iken is the Director of Information Technology in the School of Industrial and Systems Engineering at the Georgia Institute of Technology. Mark received his Ph.D. in atomic and molecular physics from Georgia Tech and was previously the directory of the Scientific Visualization Laboratory at Georgia Tech. His current areas of research include bio-medical visualization, large-scale distributed molecular relaxation/optimization processes, quantum chaology and technology enhanced education.

\section{JYE-CHYI LU}

Dr. J.-C. Lu is a Professor of Industrial and Systems Engineering at Georgia Institute of Technology. His primary area of research is in statistics and information systems engineering in design and manufacturing. He is currently working on several projects in mining large size nonstationary data and developing course materials in areas such as data mining and e-business information systems.

\section{Proceedings of the 2002 American Society for Engineering Education Annual Conference \& Exposition} Copyright $\odot$ 2002, American Society for Engineering Education 